\title{
Thoughts on screening tests in bacteriology
}

\author{
S. P. LAPAGE \\ From the National Collection of Type Cultures, Central Public Health Laboratory, Colindale Avenue, \\ London
}

Screening tests in bacteriology are not new. However, recent mechanized and automated techniques have greatly increased our technical capacity in this respect, which could lead to an uncritical extension of screening, with the accumulation of large amounts of data which are impossible to assess. Normal values must first be established and this may require detailed surveys of, for example, the antibody levels found in populations and the significance or lack of significance of particular bacteria or viruses in the material from which they are isolated. The uses to which screening tests are put need care. In Britain, the labour of routine screening of food handlers for enteric pathogens is considered scarcely worth while except in special circumstances such as contact of the food handler with relevant infectious disease (Howie, 1970). Those who press for such vast screening programmes need to say if the food handlers should be screened annually, monthly, or dailyand why one interval is chosen rather than another. On the other hand, the screening of waterworks employees to detect typhoid and paratyphoid carriers is probably worth doing because the work is not on such a scale as seriously to divert resources from more productive use.

\section{Screening of Specimens and of Microorganisms Isolated}

There are two main kinds of screening in bacteriology, first living beings and inanimate objects for the presence of an organism or evidence of infection or immunity, and secondly of isolated microorganisms, which usually involves identification and test selection but does not always do so. Both kinds may be needed in a full screening procedure, for example, of hospital staff for staphylococci and then screening the staphylococci for Staphylococcus aureus strains,

Received for publication 24 April 1971.

${ }^{1}$ Based on a talk given on 16 February 1971 at a Symposium, 'Current status and value of laboratory screening tests', held by the Section of Pathology at the Royal Society of Medicine. perhaps for a particular phagetype of Staphylococcus aureus. However, many bacteriological screening ${ }^{+}$ procedures do not require the isolation of bacteria, for example, tuberculin skin tests to select susceptible people for BCG vaccination.

The living beings screened may be man or other? animals, and the value of screening tests in veterinary medicine is well established-for example tuberculin skin tests in cattle as an aid in eradication programmes. Screening may be carried out on populations assumed to be healthy to detect unapparent or incipient disease, to assist preventiveo measures, or to find the cause of the symptoms in ans undiagnosed patient. An example of the first is theo serological screening of women antenatally foro syphilis by the Wassermann reaction. This also $\mathbb{Q}$ illustrates the need for care in the interpretation of screening tests, because a positive result might have a different meaning in a temperate compared with a? tropical country, where other diseases known to give? a positive result were endemic. In any case, more specific serological tests for syphilis, if available would be needed for confirmation. An example of as preventive screening measure would be the exam ination of infants' faeces on their admission to a children's unit for the common enteropathogenic serotypes of Escherichia coli which is only of value if facilities for their isolation exist pending the result (Rogers and Taylor, 1961). It may be difficult to decide the serotypes against which to use antiseraN and tests of the specificity of these antisera arêt needed. Screening the patient for the cause of hif symptoms is illustrated by quantitative bacteriato counts of the urine or by tests for antibodies to bac? terial or viral antigens.

The screening of inanimate objects in medicine is important and may take the form of bacteriologica? samples; but difficulties may arise from the sampling statistics, for example, such low rates of possible contamination would be expected with sterile syringes that it would probably be indistinguishable from experimental error and in such cases safe 
control and maintaining of the process of sterilization itself may be more useful. The value of sampling hospital environmental surfaces in controlling cross infection is not clearly established. It is expensive, and adequate supervision of the domestic cleaning staff may prove far more relevant and useful. If it is undertaken, testing should be concentrated on surfaces in close relation to the patient and likely to be a real hazard.

Air sampling may be of value in special circumstances but regular screening is rarely practiced because the resulting counts vary widely with the individuals present. It may be used to identify individuals likely to disperse bacteria widely. Eczematous skin detected by the naked eye may usefully direct the sampler to the proper target.

Disinfectants should be screened for their spectrum of efficiency and for their potency as well as for the absence of contaminating bacteria, though establishment of a safe process in the hospital pharmacy or ward is the aim of the latter.

Also of importance to human health and comfort are screening methods in industrial microbiology. These include the screening of foods and drugs for sterility or for pathogenic and spoilage microorganisms and the allied public health screening of water, milk, and other substances. There are many other industrial uses such as the screening of microorganisms for degradation or the production of chemical compounds which are outside the scope of this paper.

Laboratory and Hospital Screening from Records of Laboratory Results

Systems have been developed for entering the results of hospital bacteriological tests in computers. In Great Britain, Stirland, Hillier, and Steyger (1969), and Alexander, Connigale, Johnson, Poulter, and Wakefield (1970) have used off-line batch processing systems with punched cards and paper tape respectively, while Whitby and Blair (1970) use a system based on punched cards which is effectively operating in real time. Trials have been made (Lamson, 1960) of mark sensing devices with which the technician himself marks the results on a document, and these marks are read and translated by an electronic device or read directly into a computer. This system, or the use of an on-line computer terminal, eliminates errors due to transcription by clerical staff. Such systems can provide ready analysis to screen the hospital or compare individual wards or other areas, for example, for the distribution of pathogens, for changes in antibiotic resistance, for response to treatment, and other studies of comparative performance. Quality control of the laboratory can be instituted, and it should be possible to develop diagnostic systems from information derived from local strains.

\section{Screening of Laboratory and Other Records}

Among other possible uses of screening in bacteriology is the screening of documents by systems such as key words in context. This is well known in biological abstracts, and can be used for search of other types of documents, such as accumulated laboratory results, reports of research, and even correspondence. Dammers and Gallacher (1970) at Shell Research Ltd have extended the system so that key words can be sought for by the computer.

\section{Mechanical and Automated Processes in Screening}

Williams and Trotman (1969) and Trotman (1970) have recently reviewed mechanized and automated laboratory techniques, Hill (1970) has reviewed multiple inoculation techniques, and aspects of automated serological techniques have been reviewed by Taylor (1969). The use of the AutoAnalyzer in complement-fixation tests (Vargues, Studievic, and Maupas, 1970) and of mechanical dispensers such as that devised by Dr Sequeira of Manchester are important developments.

Microscopical examination of specimens would seem suitable for automation, and the detection of tubercle bacilli stained by a fluorescent dye and examined by an automatic scanner is under investigation. Automatic scanning of the morphological features of bacteria, whether of cells or of bacterial colonies, has not yet been developed due partly to the difficulty in the separation of artefacts, the lack of suitable, defined, codable parameters for the bacterial colony, and to the great variation of colonial appearance on different media and sometimes even on different batches of nominally the same media. Also, as in many possible techniques in bacteriological screening, although the ideas are there, the application and development of suitable hardware has not yet been achieved.

Between the reception of a specimen and the conventional test results, usually available after 18 or more hours, there is great scope for automatic screening and reduction in time of testing. The screening of bacteria, after only a few hours' growth, by staining with specific immunofluorescent antibodies would seem promising, but difficulties lie in the large-scale preparation of sufficiently specific reagents, in the sharing of antigens by different microorganisms, and in the separation of specifically stained bacteria from non-specifically stained objects. Automated, accurate measurements 
of bacterial growth could also hasten results. For example, early growth could be detected in the presence of specific substrates and on different selective media. Automated systems which involve growth have been used for the screening of antibiotics for their antimicrobial activity, such as the systems described by Cobb, Crawley, Croshaw, Hale, Healey, Pay, Spicer, and Spooner (1970) in use at Boots Pure Drug Co Ltd. The system uses automatic inoculating, reading, and scanning of the results in a computer. An automatic antibiotic plate reader for antibiotic sensitivity has also been described by Grady and Sykes (1970) at the Beecham Research Laboratory.

The use in bacteriology of the Coulter counter, the operation of which depends on changes in electrical resistance as particles pass between electrodes, has been described by Hobson and Mann (1970) but there are difficulties in distinguishing aggregates of bacteria from single cells; differently shaped bacteria cannot be separated and small debris may simulate bacteria.

Isolation methods can be mechanized, and the details of a mechanical plate spreader have been described by Trotman (1967). The use of such a machine in conjunction with a set of selective and marker media might be useful, although limitations would arise from the difficulty of devising media of sufficient selectivity to grow only members of one species or genus. In a given species, some strains might fail to grow on a particular medium, like the occasional Shigella culture or strain of Salmonella pullorum which does not grow on MacConkey's medium. This raises the quantitative question: What error rate is acceptable in screening? If the laboratory reading and clerical errors total $1 \%$, the failure of $0.01 \%$ or less of the bacteria to grow may not matter. One would also like to know how much this error rate is affected by the use of different batches of media. The pathogenicity of the organism and its importance to public health also play some part in deciding what failure rate may be accepted. One would require more stringent methods for Salmonella typhi than for Shigella sonnei.

The AutoAnalyzer has been used successfully by Bettelheim, Kissin, and Thomas (1970) in the estimation of asparaginase and glutamase activity by measuring the ammonia produced. Its use in complement-fixation tests has been reviewed by Taylor (1969). Results from this instrument are recorded as a continuous graph but there are difficulties, particularly with mark 1 models, in deciding what is a peak, in identifying peaks with their associated specimens, and in ensuring a satisfactory washout between samples-a point which affects the speed of sampling. Basically, the con- version of what is essentially a digital process, that is, separate tests, to an analogue process seems $\underline{0}$ undesirable, and the future may lie in automatic discrete analysers, which have been reviewed by $\stackrel{?}{+}$ Northam (1969). With these analysers tests are? carried out in separate vessels which are then read in succession by a photo-electric cell. However, so $\frac{\bar{\rho}}{\overrightarrow{0}}$ far as I know, all the present discrete analysers use $\stackrel{\mathbb{D}}{\AA}$

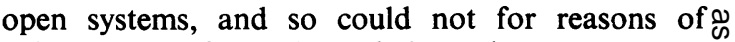
safety be used for pathogenic bacteria.

An open mind is needed when considering laboratory automation for the future. The usual $\vec{\omega}$ methods of testing may require changing and the $\stackrel{S}{S}$ potentialities of the automated apparatus itself may용 suggest new tests. For example, no use seems to in have been made, in the identification of bacteria, of $\vec{r}$ the electrical charge on the bacteria of different $A$ species; this might prove a particularly suitable $\AA$ test in an automated procedure. This reminds one응 of the story of the computer which was programmed to recognize people by measuring their character- $c$ istics, and to choose the most economically satisfactory set. It was found that the computer was re- $\vec{\varphi}$ cognizing them by a characteristic no human would have been likely to use, the slope of the shoulders.

\section{Constitutive Techniques in Screening}

For want of a better expression, another class of newer screening tests may be called 'constitutive techniques', for example, gas chromatography, $\overrightarrow{0}$ with or without mass spectrometry, gel electro- 3 phoresis, and infrared absorption spectra. Few of these highly sophisticated physico-chemical techniques are yet in a stage of development suitable for $\overline{0}$ use in the diagnostic laboratory but they have considerable potential screening applications. Similarly, genetic techniques, such as estimation of the percentage of guanine and cytosine in the DNA, $₹$ DNA hybridization, and similar investigations of the genome may ultimately be simplified.

\section{Screening of Isolated Organisms by Test Selection}

Test selection is part of the process of screening bacteria isolated. The choice of the set of screening $\omega_{0}$ tests is usually one which will identify certain organisms, such as Salmonella or Shigella, and? exclude others. Such tests do not usually identifyơ the excluded organisms and may fail to recognize the desired organisms if these are aberrant in achosen test, such as the rare strain of Salmonella which produces indole. For economical reasons, $\frac{?}{\mathbb{D}}$ such sets of tests have been compressed so that one $\stackrel{0}{-}$ tube is made to yield the results of several tests, 
eg, triple sugar-iron agar, or the familiar two-tube tests for enterobacteria (Gillies, 1956). Many schemes based on these multiple methods have been developed for the rapid detection of particular bacteria, and some include the use of paper-strip tests as well as conventional tests (Borchardt, 1968; von Graevenitz, 1968). Relatively simple devices have been designed for multiple tests, for example, flat plastic containers holding a number of discs each of which contains the reagent for a different test. Measured amounts of bacterial suspension are absorbed by these discs and the tests take place on them during a suitable period of incubation. This type of test can be refined by the addition of automatic reading and in some cases the results are available in hours, as in the scheme of Buissière and Nardon (1968).

It is usual to carry out those tests necessary to identify bacteria likely to be present in the specimen. If tests can be selected early in the identification process, a saving in the total number of tests needed can be achieved. A computer can help here and our system in the Computer Trials Laboratory at Colindale (Lapage, Bascomb, Willcox, and Curtis, 1970) is as follows: the sender performs a limited set of tests and sends the results to us. We compare them, by means of a computer with a table of taxa of bacteria, versus the results that strains of these taxa are expected to give in those tests. The strain is then either identified or further tests are selected by the computer. The results are printed out, edited, and returned to the sender who carries out the further tests if any have been selected. Results of these further tests are sent to us and the process is repeated.

During the identification in the computer, the identification scores for each taxon in the table are calculated, and when the tests are selected the computer selects those tests which differentiate between the most likely taxa suggested by the prior identification process. Hence the tests are selected during the process of identification, and the path which the identification procedure is following can be observed. We have shown that, of the 50 or so tests thought to be required to identify a 'difficult' strain of Gram-negative rod, 36 tests will guarantee the same result, but of course, not the same 36 tests in each case. In addition allowance is made for the fact that tests may duplicate information contained in previous tests. When the test with the highest differentiating power has been selected, the taxa which it would separate are stored and the next test chosen will be one which separates further among these. A test which separates only the same taxa as the first test would not be chosen even if it had high overall differentiating power.
Since the computer selects tests at a stage in the identification when some of the tests have been carried out it is working at a disadvantage. It is easy to arrange the tests in the table in rank of their overall differentiation between the taxa. A possible strategy would be to begin with a few tests of high value in differentiation, perform these, select the next batch of tests by computation on the results of the first few, then another batch by a similar process, and so on. Thus each batch of a few tests would be selected by the results of the previous tests. However, it is clear that this is an unreal situation since the frequency of appearance of different kinds of bacteria varies in the different types of specimens, for example, in sputum or faeces. Hence a battery of initial tests which might be suitable to differentiate between the bacteria likely to be present in one kind of specimen would not necessarily be the most suitable set for a specimen of another type. When we have collected enough strains from the various types of specimen to estimate the frequency with which the various species appear in our series, we shall be able to devise different computer test-strategies for each type of specimen.

The problems of standardization of bacteriological tests are difficult in practice. In our series of 13,000 tests we found a difference of $8 \%$ between the results of the sending laboratories and our own laboratory, even though the methods are, in general, similar. This is not surprising in view of the results of other studies on inter-laboratory differences. In the International Streptomyces Project, in which both strains and media were exchanged, differences as great as $30 \%$ were observed, perhaps because many morphological tests were used, such as colour. An overall rate of difference of this kind would render identification virtually impossible. We find that our rate of $8 \%$ interferes with identification in only a small proportion of the strains. However, tests vary in their reliability. The worst test in our series was the detection of hydrogen sulphide production by lead acetate papers; only this test shows a difference as high as $30 \%$. Production of catalase, on the other hand, revealed only a $1 \%$ difference between our results and those of the sending laboratories. Most of the tests show a level of difference below $12 \%$ and those above this level are usually known to be difficult to reproduce, or else different methods are often employed. However the necessity for standardized tests cannot be overstressed.

Originally, the matrix of expected test results versus taxa was made from the literature, from NCTC records, and from the records of a few other reference laboratories at Colindale. Two years and a thousand strains later, we have rewritten the matrix with values derived from our standardized 
methods of testing, thus improving success in identification with 'difficult' fermentative Gramnegative rods from about $70 \%$ to $90 \%$. When automated screening tests are extensively used, it will be essential to ensure that tests are standardized as far as possible though I think that there will always be some variation. Bacteria are living organisms, highly sensitive to slight changes in media, physical conditions of growth such as temperature, $p \mathrm{H}$, or gaseous conditions, and their enzymes may be affected by trace elements. This is often forgotten and we expect them always to behave typically. Of course, this biological variation should also be taken into account when considering whether low level errors for other reasons are to be discounted.

Perhaps the future of automated identification lies in the conjunction of a computer with an automated testing machine such as a discrete analyser, into which the bacterial suspension would be introduced. A few selected tests would be carried out and the results entered into the computer which would indicate the next tests to do. Thus identification could proceed in the most economical series of steps. This, however, is perhaps a view limited by our present methods of testing. In the course of time, present tests may be replaced by constitutive tests such as gas chromatography, gel electrophoresis, and similar physico-chemical techniques.

In conclusion, it seems to me that before embarking on a screening procedure intended to lead to action, we need to know what are the levels in healthy people and the returns compared to the labour put in. Are we likely to create problems and likely to meet a situation we cannot deal with? For example, if a rare pathogen is found to be widely distributed in a non-epidemic situation, what then do we do?

In an article of this kind, only examples can be chosen. The author begs for indulgence for the many omissions of techniques in their infancy or under development, particularly screening methods and pattern recognition, and of the many ingenious and elegant machines which have been devised.

I should like to thank Sir James Howie, Drs M. T. Parker, B. Rowe, and C. E. D. Taylor for reading the manuscript and providing advice and criticism.

\section{References}

Alexander, M. K., Connigale, J., Johnson, T., Poulter, I. R., and Wakefield, J. (1970). A data processing system for hospital bacteriology. J. clin. Path., 23, 77-80.

Bettelheim, K. A., Kissin, E. A., and Thomas, A. J. (1970). An automated technique for the determination of ammonia produced by bacteria. In Automation, Mechanization and Data Handling in Microbiology, edited by A. Baillie and R. J. Gilbert, (Society for Applied Bacteriology Technical Series
No. 4), pp. 133-136. Academic Press, London.

Borchardt, K. A. (1968). Simplified method for identification of enteric and other Gram-negative bacteria using reagent impregnated strips. Amer. J. clin. Path., 49, 748-750.

Buissière, J., and Nardon, P. (1968). Microméthode d'identification des bactéries. I. Intérêt de la quantification des caractères biochimiques. Ann. Inst. Pasteur, 115, 218-231.

Cobb, R., Crawley, D. F. C., Croshaw, B., Hale, L. J., Healey, D. R., ত Pay, F. J., Spicer, A. B., and Spooner, D. F. (1970). The application of some automation and data handling techniques $\vec{T}$ to the evaluation of antimicrobial agents. In Automation, $\mathbb{D}$ Mechanization and Data Handling in Microbiology, edited by $\frac{\varrho}{\Omega}$ A. Baillie and R. J. Gilbert, (Society for Applied Bacteriology $\backsim$ Technical Series No. 4), pp. 53-76. Academic Press, London.

Dammers, H. F., and Gallagher, P. J. (1970). Computer use in $\vec{\odot}$ information and data handling. In Automation, Mechanization -1 and Data Handling in Microbiology, edited by A. Baillie and $\vec{\omega}$ R. J. Gilbert, (Society for Applied Bacteriology Technical $\mathscr{W}$ Series, No. 4), pp. 33-51. Academic Press, London.

Gillies, R. R. (1956). An evaluation of two composite media for $\frac{7}{0}$ preliminary identification of Shigella and Salmonella. J. clin. iv Path., 9, 368-371.

Grady, A. E., and Sykes, D. A. (1970). Automated reading of large ir assay plates. In Automation, Mechanization and Data Handling it in Microbiology, edited by A. Baillie and R.J. Gilbert, (Society $\underset{\mathbb{A}}{\mathbb{R}}$ for Applied Bacteriology Technical Series, No. 4), pp. 77-83. Academic Press, London.

Hill, I. R. (1970). Multiple inoculation technique for rapid identi- ב fication of bacteria. In Automation, Mechanization ard Data Handling in Microbiology, edited by A. Baillie and R. J. Gilbert, $ᄃ$ (Society for Applied Bacteriology Technical Series, No. 4), pp. 175-189. Academic Press, London.

Howie, Sir J. (1970). Bacteriological checks on food handlers. (Letter.) Brit. med. J., 2, 420.

Hobson, P. N., and Mann, S. O. (1970). Applications of the Coulter Counter in microbiology. In Automation, Mechanization and Data Handling in Microbiology, edited by A. Baillie and R. J. Gilbert, (Society for Applied Bacteriology Technical Series, No. 4), pp. 91-105. Academic Press, London.

International Business Machines (1962). General Information Manual (KWIC) Indexing. International Business Machines Program Information Department, White Plains, New Jersey.

Lamson, B. E. (1966). Data Processing in a Medical Center. Progress Report, 1966. University of California, Los Angeles.

Lapage, S. P., Bascomb, S., Willcox, W. R., and Curtis, M. A. (1970). Computer identification of bacteria. In Automation, Mechanization and Data Handling in Microbiology, edited by $\mathbf{A}$. Baillie and R. J. Gilbert, (Society for Applied Bacteriology Technical Series No. 4), pp. 1-22. Academic Press, London.

Northam, B. E. (1969). Discrete analysis systems. J. clin. Path., 22, $\frac{\Omega}{0}$ Suppl. (Coll. Path.), 3, 42-50.

Rogers, K. B., and Taylor, J. (1961). Laboratory diagnosis of gastroenterit is due to Escherichia coli. Bull. Wld Hlth Org., 24, 59-71.

Stirland, R. M., Hillier, V. F., and Steyger, M. G. (1969). Analysis of hospital bacteriological data. J. clin. Path., 22, Suppl. (Coll. Path.), 3, 82-86.

Taylor, C. E. D. (1969). Serological techniques. J. clin. Path., 22, 음 Suppl. (Coll. Path.), 3, 14-18.

Trotman, R. E. (1967). Automatic serial diluting: an instrument for $D$ use in bacteriological laboratories. J. clin. Path., 20, 770-776. 음.

Trotman, R. E. (1970). Automatic methods in diagnostic bacteriology. In Automation, Mechanization and Data Handling in Micro- $\mathrm{N}$ biology, edited by A. Baillie and R. J. Gilbert, (Society for Applied Bacteriology Technical Series No.4), pp. 211-221. N Academic Press, London.

Vargues, R., Studievic, C., and Maupas, P. (1970). A new rapid $\omega$

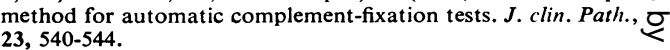

Von Graevenitz, A. (1968). Identification of non-fastidious Gram-co negative rods with delayed or absent lactose fermentation: a simplified system for the hospital laboratory. Amer. J. med. Technol., 34, 459-466.

Whitby, J. L., and Blair, J. N. (1970). A computer-linked data process- $\square$ ing system for routine hospital bacteriology. In Automation, $\overline{\mathrm{O}}$ Mechanization and Data Handling in Microbiology, edited by $\frac{\vec{D}}{(1)}$ A. Baillie and R. J. Gilbert, (Society for Applied Bacteriology Technical Series No. 4), pp. 23-32. Academic Press, London. (D)

Williams, R. E. O., and Trotman, R. E. (1969). Automation in diag- Q nostic bacteriology. J. clin. Path., 22, Suppl. (Coll. Path.), 3, 8-13. 